\title{
Faculty persistence with research-based instructional strategies: a case study of participation in a faculty online learning community
}

\author{
Adriana Corrales ${ }^{1 *}$, Fred Goldberg ${ }^{2}$, Edward Price $^{3}$ and Chandra Turpen ${ }^{4}$
}

\begin{abstract}
Background: Incorporating research-based instructional strategies (RBISs) into college classrooms is essential for improving learning outcomes. However, the rate of implementation of new strategies is quite low. The development and dissemination model of introducing faculty to new strategies has shown to be inadequate in encouraging uptake and consistent use of those strategies. This model lacks the ongoing support that has shown to be exceedingly important in the adoption and persistent use of new strategies. In addition, this model ignores the necessity of adaptation of RBISs due to differences in teaching situations including availability of particular resources or different student populations. Faculty online learning communities (FOLCs) are online collaborative faculty groups that provide continued support in order to fill this gap. This case study explores one FOLC member's adoption of a research-based physical science curriculum as they reflect on their teaching experiences. We operationalize Rodgers' cycle of reflection to make sense of these changes. Specifically, the study aims to understand how the focal faculty member's participation in reflection in the context of the FOLC changes over time.

Results: Analysis via Rodgers' reflection framework revealed changes in the way Leslie participated in reflection within the context of the FOLC. The faculty participant optimized her teaching practice through iterative cycles of reflection with the FOLC cluster. As a result, she became more satisfied with the curriculum and her implementation over time.

Conclusions: Faculty encounter challenges when adopting RBISs that must be addressed in real time. Reflection accompanied by ongoing community support via the Next Gen PET FOLC can provide support for changes in practice and increase faculty satisfaction with RBISs. The results contribute to evidence that community building and ongoing support in implementing new curricula is integral to the adaptation process, and FOLCs can provide that support to sustain long-term change.
\end{abstract}

Keywords: Faculty online learning community, Reflection, Research-based instructional strategy, Faculty change

\section{Introduction}

Discipline-based education research (DBER) has resulted in many research-based instructional strategies (RBISs), yet the number of educators implementing such strategies remains disappointingly low (Henderson, Beach, \& Finkelstein, 2011;

\footnotetext{
*Correspondence: adricorr7@gmail.com

${ }^{1}$ Center for Research in Mathematics and Science Education, San Diego State University, 6475 Alvarado Road, Suite 206, San Diego, CA 92120, USA

Full list of author information is available at the end of the article
}

Henderson, Dancy, \& Niewiadomska-Bugaj, 2012; Seymour, 2002). The basic model of RBIS development and dissemination is not sufficient to encourage faculty to use and persist in using RBISs. In education research, RBIS development is the production of a new pedagogical tool, strategy, or curriculum. and dissemination is the process by which potential users of the strategy are made aware of it. Many faculty members are aware of RBISs but have not implemented such strategies-often citing time as a major barrier 
(Henderson \& Dancy, 2007). Faculty that do implement RBISs often discontinue use or make modifications, sometimes in ways not consistent with the developer's design. Given the potential positive impact of RBISs (Freeman et al., 2014), there is a need for better understanding of the adoption process and how to more effectively support faculty in implementing RBISs. Though there is some evidence that faculty who persist are already highly interested in teaching research (Henderson et al., 2012), it is likely not the only factor contributing to continued use of a teaching strategy or curriculum. It is often suggested that sustained professional development and support, particularly from a community of peer faculty, is necessary for faculty to continue using RBISs (Darling-Hammond \& Richardson, 2009; Henderson, Cole, Froyd, Friedrichsen, \& Stanford, 2016; Sturtevant \& Wheeler, 2019). With continued support and community, faculty have the opportunity to troubleshoot ideas and resolve issues that they otherwise may not have been able to on their own. This is part of the rationale for the creation of faculty online learning communities (FOLCs), which bring together educators to learn from each other and share resources. FOLCs are modeled on Faculty Learning Communities (Cox, 2004) but exist online among geographically dispersed faculty. A FOLC is the context for the present study.

This case study provides a detailed description of one faculty member's experience implementing a new curriculum while participating in a FOLC. After describing the context and setting of this study, we draw on reflection literature to better understand the personal and social contributions that may have supported her persistence in using a particular research-based curriculum despite initial difficulties. Personal characteristics of the educator, her reported classroom experiences, and interactions within the FOLC will be explored to describe the focal faculty participant's change in participation in reflection, which coincided with her eventual satisfaction and appreciation of the Next Gen PET curriculum. This study aims to provide insight into the process of adopting RBISs and the impact of ongoing professional support and development. Findings will be of interest to curriculum developers, professional development providers, and higher education change agents.

\section{Setting and context}

The educator of interest, Leslie ${ }^{1}$, is a part of a larger group of faculty who are participating in a faculty online learning community. FOLCs are a type of faculty learning community (FLC), in which faculty primarily meet online through both synchronous meetings and asynchronous communication platforms. The goal of such a community is to provide a space for long-term professional development and

\footnotetext{
${ }^{1}$ This name is a pseudonym
}

course transformation to improve teaching and learning, similar to a traditional FLC (Cox, 2004). This is not to be conflated with a full online learning community, which is a model of online learning in higher education for students as response to difficulties with online learning such as a lack of community and social support (Blayone, Barber, DiGiuseppe, \& Childs, 2017). It has been shown that FLCs increase faculty interest in teaching and learning, aid in the implementation of new teaching practices, and support sustained teacher change (Dancy, Lau, Rundquist, \& Henderson, 2019; Emerson \& Mosteller, 2000; Sawada et al., 2002). Recently, Tinnell, Ralston, Tretter, and Mills (2019) have reported on the types of institutional and community supports, via an FLC, needed to promote sustained pedagogical change and overall positive outcomes of the FLC. Results showed that participation in the FLC promoted accountability in teaching and strengthened faculty peer relationships.

The FOLC model of professional development for educational change builds on the traditional FLC design but is different in two key ways: (a) FOLCs meet online rather than in person and (b) a FOLC is comprised of faculty from multiple institutions, allowing for more targeted professional development (Dancy et al., 2019). This particular FOLC was launched with 48 members and over 3 years has varied between 46 and 50 members due to a small number of members leaving and a few new faculty joining. Active members were separated into five clusters, each with two or three cluster leaders. The cluster leaders are faculty who have extensive experience with some version of the shared curriculum being implemented (described in the following paragraph). Due to scheduling logistics, most clusters meet in two smaller subgroups every other week, as is the case with the cluster of interest in this study. Additionally, the common modus operandi for the cluster of interest is that cluster leaders facilitate a "round-robin" reporting out of cluster members' teaching experiences. The online meetings tend to last about an hour with a range of 3 to 8 cluster members per meeting. The cluster groups also communicate asynchronously via email and through an online collaboration hub where they can post comments, links, documents, and other resources.

All members of this FOLC are implementing the same curriculum, Next Generation Physical Science and Everyday Thinking (Next Gen PET) (Activate Learning, 2018). This curriculum is the newest set in a series of physics and physical science curricula created for teaching pre-service elementary teachers (Goldberg, 2015; Goldberg, Robinson, Otero, Kruse, \& Thompson, 2008; Goldberg, Robinson, Price, Harlow, \& McKean, 2012; Harlow et al., in press), which has been modified to more specifically align with the Next Generation Science Standards (NGSS) framework (Activate Learning, 2018; 
Lead States, 2013). Much like previous versions of the curriculum, Next Gen PET incorporates the following innovative learning strategies: (1) supporting claims through evidence, (2) developing scientific ideas through group consensus, and (3) allowing science ideas to emerge through engagement in science practices (Goldberg, Otero, \& Robinson, 2010; Goldberg, Price, Robinson, Boyd-Harlow, \& McKean, 2012). This is done through small group work and whole class discussions, among other strategies, with the intent of shifting authority from the instructor to students using evidence to support their ideas. The curriculum materials also include teaching and learning activities, which serve to connect student learning in class to K-12 teaching practices. As well, online videos, supplemental information, and online homework assignments, called extensions, are provided. The curriculum includes a set of five modules: (1) magnetism and static electricity; (2) energy and interactions; (3) forces and interactions; (4) waves, sound, and light; and (5) matter and interactions. Each module includes two units, and any of the ten units can be ordered independently to suit the needs of the class. Next Gen PET comes in two versions, a studio-style version for smaller lab-style classes and a lecture-style version for large classes in lecture hall settings. Both types incorporate the previously mentioned learning strategies but in different ways to suit the class size and classroom structure. Evaluation of student outcomes indicates that students' experience increases in conceptual understanding with this curriculum (Engelhardt, et al., 2018; Smith \& Wingard, 2019; Otero \& Gray, 2008).

This curriculum provides a flexible set of materials for faculty to adapt to the physics or physical science classes for elementary education and general education students that is more student-centric. However, because the curriculum assumes that students take on more responsibility for their own learning, the instructor needs to take on a different role than in a traditional lecture-style course (Goldberg et al., 2010; Goldberg, Price, et al., 2012). Hence, it is not a trivial curriculum to implement, and faculty are expected to benefit from ongoing support, thus motivating the formation of a FOLC.

\section{Literature review and conceptual framework}

Educators who adopt RBISs to replace traditional approaches engage in the process of changing their instructional practices and conceptions. Reflection may play a key role in that change (Rodgers, 2002b). Reflection has been regarded as an elusive and ill-defined construct and is the subject of multiple reviews calling for a clear conceptualization of reflection with well-defined characteristics (Jay \& Johnson, 2002; Rodgers, 2002a). Despite critiques of the conceptualization of reflection, aspects of reflective practice have been connected to effective teaching, teacher professional development (PD), and teacher change (Bali \& Caines, 2018; Rodgers, 2002a, 2002b), though the persistence of that change over time is uncertain.

We emphasize reflection as an individual and collaborative process, in which one reevaluates previous experiences, events, and beliefs. This action may result in a change in one's views of a situation and potentially lead to changes in teaching practices (Jay \& Johnson, 2002; Mälkki \& Lindblom-Ylänne, 2012; Rodgers, 2002a; Wesley \& Buysse, 2001). Carol Rodgers' (Rodgers, 2002a; Rodgers, 2002b) reworked conceptualization of the characteristics and phases of reflection, adapted from the original work of John Dewey $(1933,1938)$, serves as the main theory from which we derive our conceptual framework. Rodgers describes reflection via four major criteria: (1) reflection as a meaning making process, (2) reflection as a rigorous process, (3) reflection through community, and (4) reflection as a set of attitudes (Fig. 1). Criterion one implies that reflection is a process in which one experiences or interacts with something and subsequently makes sense of the situation by making connections between new experiences and prior knowledge and experiences. Essentially, reflection is the process of the construction and restructuring of experience and knowledge which contributes to the meaning of an experience. Criterion two implies that reflection goes beyond mulling something over. Reflection is an intentional act in which one reconsiders their beliefs and practices in order to move from a state of "disequilibrium" to "equilibrium." This means that one has encountered a perturbing experience, which brings into question one's current beliefs, knowledge, and ideas and thus some directed reflection must occur to resolve this conflict. Dewey and Rodgers reason that reflection is the intentional and pointed process of making sense of that conflict.

Rodgers highlights the importance of reflection in community. Reflection with oneself is beneficial, however is not complete without reflection in a community of others with differing viewpoints who can reveal holes in one's own thinking. Discussion of issues and ideas with others can help one see experiences from other perspectives and can also validate one's experiences. Reflection in a community requires a supportive environment in which everyone is willing to share with others, while also acting individually in their respective classrooms. The importance of community and collaboration in reflection is a common theme among reflection research. Noffke and Brennan (as cited in Beauchamp, 2015) assert that in order for reflection to be effectively integrated into teacher education and PD programs, the process of reflection must occur both on the individual and social planes. This sentiment is echoed by the work of Wesley and Buysse (2001), who emphasize that individual reflection is just a part of the full picture. Reflective practitioners engage with 


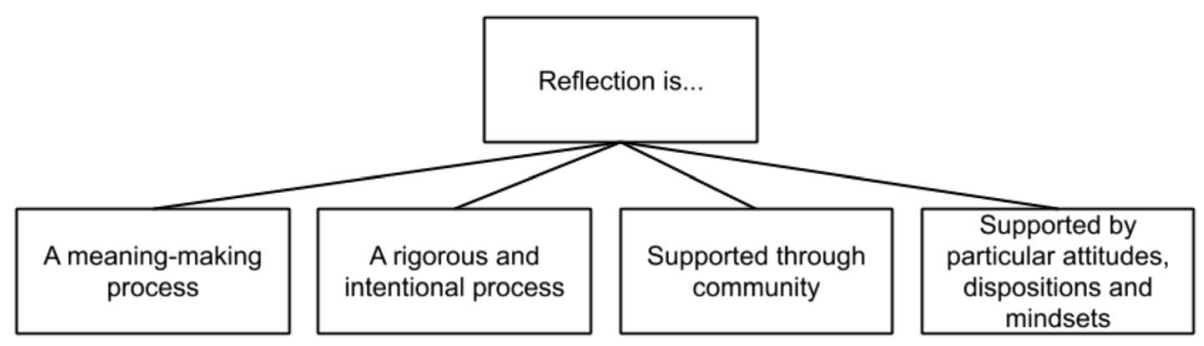

Fig. 1 This graphic is an original depiction of the components of reflection from Rodgers' (2002a) work on the reflective cycle in practice

others to bring forth many perspectives and reflect beyond their own ideas and experiences. This collaboration is essential for reflection to help participants critically analyze personal experiences as well as moral and ethical outcomes of their work. Hatton and Smith (1995) emphasize the importance of critical friends in reflection. Critical friends are trusted others who are both sympathetic and constructively critical. These critical friends are willing to engage in dialog truthfully and with vulnerability. They may bring forth different viewpoints for the group to consider and reflect upon regarding planning for teaching, implementation, or evaluation as well as allowing for the formation of valuable social connections (Bali \& Caines, 2018). Reflection on the social plane gives a voice to one's own ideas and allows others to be heard. In this way, participants in reflection may feel valued and value the ideas of others. From this point of view, a FOLC can be seen as a group of critical friends supporting mutual reflection and growth.

One must also hold particular attitudes in order to engage in reflection. We consider attitudes broadly to include ways of thinking and feeling, disposition, and mindset. According to Rodgers (2002a), reflection is more likely to occur in those that exhibit the following attitudes: (1) whole-heartedness or genuine interest, (2) curiosity of the subject matter, (3) directness or lack of self-consciousness, (4) open-mindedness or an amenability to new ideas, and (5) responsibility for change and growth. Jay and Johnson (2002) make similar claims, stating that reflective practitioners should approach conversations about teaching with open-mindedness, responsibility, and sincere commitment. While Rodgers does not explicitly connect attitudes to mindset, we see this as a relevant construct for thinking about the roles of attitudes in reflection. Dweck (2008, 2014) describes mindset as one's beliefs about one's own attributes and abilities. At the extremes, these beliefs are described as either a fixed or growth mindset. People with a fixed mindset believe that one's basic abilities and talents are generally unchanging, often do not respond well to struggle, and are more likely to give up as they see their abilities as fixed and do not see opportunity for growth. Teachers with this mindset may have difficulties persisting in using new strategies because it may require new facilitation or classroom management skills that instructors may not have experience with. As a result, mindset may be a contributing factor when faculty do not persist in using RBISs as it could affect how they approach developing new skills. Conversely, those with a growth mindset believe that one's own abilities can be developed through effort and persistence (Dweck, 2008, 2014). Thus, deficiencies are seen as opportunities to improve rather than barriers to success. Gero (2013) found that teachers with a growth mindset are more likely to face teaching struggles head-on and discuss those struggles with other teachers. A growth mindset can be difficult to sustain though some strategies for doing so include creating small quantifiable goals and reflecting on everyday teaching practices with others. A community of critical friends (Hatton \& Smith, 1995) may provide support for maintaining a growth mindset and as a result can promote reflection through support of the required attitudes for reflection.

Rodgers (2002b) operationalized her detailed conceptualization of reflection in the context of teacher PD in order to instruct teachers in a systematic procedure for engaging in reflection. This framework for reflection is outlined as a set of steps (or phases), but is cyclical in nature and as such occurs iteratively. One can move forward or backward within the cycle and as such is not thought of as a rigid ordering of steps. Rodgers' (2002b) reflective cycle consists of four phases: (1) presence in experience, (2) description of experience, (3) analysis of experience, and (4) experimentation. Presence means seeing learning and/or making the effort to see learning and not making assumptions about learning based on perceived engagement. Present teachers center learning rather than teaching, are mindful in the moment, and have a "nonjudgmental" attitude toward learners in order to ascertain whether students are learning and why or why not. In practice, educators may focus more on their teaching and instructional planning (Erdmann, Miller, \& Stains, 2020) and as a result not exhibit presence in the classroom. Present teachers attend to and often elicit informal student feedback in order to better understand student learning outside of summative assessments.

When reflecting, teachers must then describe their experience either to themselves or more likely with other educators. Rodgers (2002b) emphasizes the difficulty in 
separating description from interpretation. One must work to refrain from introducing biases and personal interpretation to a situation upon describing experiences in the classroom. Without guidance in this regard, reflections are often fully situated within one's personal feelings (Erdmann et al., 2020). Describing moments with others can mitigate this issue through probing questions and discussion. As others infuse their own ideas and viewpoints, the originator of the story is able to separate their interpretation from a detailed and unbiased description of events, which involves nuance and moves beyond one's limited perceptions of the situation. Through engagement in this process, educators can better integrate different viewpoints in their own thinking and describe their own experiences in more complex ways.

Following a detailed description, one can move to the analysis of a situation. Often educators will jump too quickly to solutions before fully describing and decomposing a situation. Thus, at times educators oscillate back and forth between the two stages. However, as educators intentionally practice generating descriptions without interpretation, descriptions become more nuanced and detailed. In the analysis of experience, teachers think critically and create theories or explanations regarding their experiences to address problems or potentially assess what is or is not beneficial in the classroom. This step involves incorporating differing perspectives as well as referencing and operationalizing theory from education research to inform a change in practices. Analysis of experience can lead to expanding of one's way of making meaning of an experience and can lead to the formulation of a plan for experimentation. This leads to the fourth step: experimentation. Experimentation is the process of taking deliberate and informed actions in the classroom. Upon taking action, if one is present, the experience can serve as the first step in the reflective cycle and the process begins again. Thus, a cycle of experience, reporting out, analysis, and action can lead to changes in teaching practice and potentially broader teacher change.

The connection between reflection and sustained teacher change is the focal point of this study. Do teachers undergo broader teacher change as they engage in multiple cycles of reflection? The concept of teacher change has been conceptualized and operationalized in various ways (Clarke \& Hollingsworth, 2002), making it difficult to truly capture what teacher change means. In this study, we take teacher change to mean "change inevitably through professional activity" (Clarke \& Hollingsworth, 2002). In this case, the professional activity equates to participation in the FOLC while teaching. Many models for change exist in the literature including the Interconnected Model of Teacher Professional Growth (Clarke \& Hollingsworth, 2002), Guskey's Model of Teacher Change
(Guskey, 2002), and Henderson and Dancy's (2008) model of the change process. Most recently, Czajka and McConnell (2016) utilized the Interconnected Model as an analytical tool to assess pedagogical change in one faculty member participating in a collaborative teaching PD experience. We see parallels from each model to our study; however, we argue that Rodgers' (2002b) cycle of reflection best captures the iterative process of reflection and change that occurs regarding one particular faculty member as she interacts with other members of the FOLC over a 2-year span. In addition, the reflection model represents the multi-step process in which faculty interact with each other to reason about and reflect on their practice before experimenting, which we do not see in other models.

Our conceptual framework integrates the four criteria of reflection from Rodgers (2002a) and the reflective cycle (Rodgers, 2002b) to describe a focal faculty member's change in participation in reflection over time as a community of peers supports her in implementing a new curriculum. We will integrate the criteria of reflection as we describe how the focal faculty participant (Leslie) engages in the cycle of reflection in the context of online FOLC meetings. This will provide evidence of a possible outcome of FOLC participation as it relates to reflection and teacher change. The research question we address in this study is the following: How does Leslie's participation in the phases of reflection, in the context of the FOLC, change over time?

\section{Methods}

\section{Research context}

This study is part of a larger research project focusing on a network of FOLC clusters implementing the same curriculum. The Next Gen PET research team is comprised of multiple researchers exploring multiple lines of research in the context of the Next Gen PET FOLC clusters. The project research effort centers on faculty change, curriculum dissemination, and educational transformation. Overarching research questions address how participation in the community affects faculty implementation, how faculty change over time within the FOLC, the effectiveness of this approach as a mechanism for educational transformation, and the broader impact on faculty outside the FOLC. Data sources available to the entire research group include recordings of online meetings and surveys of and interviews with participating faculty.

\section{Data collection}

Data collection occurred at the onset of the formation of the Next Gen PET FOLC. This included recordings of introductory summer workshops, bi-weekly FOLC cluster meetings, general survey data, and introductory individual interviews. Of the five clusters that comprised the full FOLC, two clusters were selected as focal clusters 
which included faculty members focused on implementing both curriculum formats. During the 2017-2018 and 2018-2019 academic years, video recordings of cluster meetings from the focal clusters were monitored for interesting comments or exchanges. Specifically, meetings were monitored for constructs described by Horn and colleagues for conceptualizing teacher workgroup conversations (Horn, 2007; Horn \& Little, 2010; Horn et al., 2017), as well as general non-specific "interesting" exchanges. Interesting exchanges in the context of the overall goals of the Next Gen PET project include conversations regarding professional growth, faculty adoption of RBISs, and the FOLC as a mechanism of faculty support. The participants in attendance, the major topics discussed, and general impressions were recorded for each meeting in an activity log. This log was available to all members of the research team and was not tailored to this particular study. The use of Horn's framework is an artifact of intersecting lines of research within the larger research team and is not the focus of this case study.

In addition to meeting data, the research team collected video data of the introductory summer workshops. The summer workshop refers to a 2-day workshop in which FOLC members, cluster leaders, and the project team met to discuss initial implementation strategies and concerns of the curriculum prior to implementing the curriculum. Field note observations were also recorded during the workshop. Pre and post workshop surveys were administered and provided insight into FOLC members' dispositions about the curriculum and teaching in general. The surveys were not designed for this particular case study but were accessed to support the focal faculty participant's claims and selfreported experiences during FOLC meetings.

A semi-structured individual interview (Bernard, 1988) was conducted in the summer after the end of the 20172018 academic year, as part of a larger set of interviews with select cluster members (including Leslie) and cluster leaders. These interviews explored attitudes about the FOLC, the curriculum, and teaching. The interview protocol was developed through discussions among the research team. The protocol was not designed for this specific study as the interviews were meant to aid multiple lines of research. The inclusion of this data in the case study was justified through the inclusion of questions related to changes in attitudes and practices and reflectiveness as a whole (see supplemental material). We were unable to conduct a follow-up interview due to lack of access to participant.

\section{Faculty participant}

After examining the activity log generated for each focal cluster, a faculty participant of interest, Leslie, was identified (Creswell \& Poth, 2017). A number of factors motivated interest in Leslie as the focal participant of this case study. The types of issues and experiences she shared in the cluster meetings seemed to change over time. In addition, Leslie was fairly forthcoming with her experiences and was vocal and clear about her thoughts and opinions throughout the meetings. She is currently a full-time faculty member in the physics department at a 4-year university on the east coast. Over the 2-year period of this case study, she has been an active member of the FOLC and has taught both prospective education majors and general education students in this time. She is part of the lecture-style cluster in the FOLC and teaches mainly the lecture-style version with some elements of the studio-style version of the curriculum. She selfidentified as having an active learning teaching style prior to joining this group according to the one-on-one interview (see supplemental material) and pre/post workshop surveys. She had not taught this specific curriculum or one if its previous iterations prior to becoming part of the FOLC.

\section{Data analysis}

In accordance with a case study approach, multiple data sources were accessed (Creswell \& Poth, 2017). A data matrix of FOLC meeting transcripts, the semi-structured interview transcript, the Next Gen PET summer workshop video recording and field notes, and the pre/post workshop surveys were collected. A thorough review of the data matrix was conducted to identify moments where Leslie shared her teaching experiences with the cluster. Only meetings where Leslie participated were included in the analysis (Table 1 ). We provide a rough description of each of the cluster meetings and other data sources. It should be noted that in the 2017-2018 academic year the cluster met twice a month, while in the 2018-2019 academic year the cluster met once a month.

After identification of key moments in which Leslie shared with the group, these interactions were analyzed via Rodgers' (2002a, 2002b) criteria for reflection and cycle of reflection. Our data elaborates on the original Rodgers' cycle to include specific actions that the focal faculty member takes throughout her participation in the FOLC as depicted in Fig 2. Faculty are present in the classroom when they make an effort to see learning, often through eliciting student feedback. As well, the expectation of reporting to a group may promote presence. Participation in the bi-weekly FOLC meetings may also support description and analysis, which is often met with questioning and the integration of various viewpoints. This leads to critical thinking and the creation of theory in the form of actionable steps. Deliberate action and change in practices are often revisited via reflection, leading to another cycle. After multiple iterations of the cycle over time, with support from a community of peers (FOLC cluster), broader teacher change can occur. 


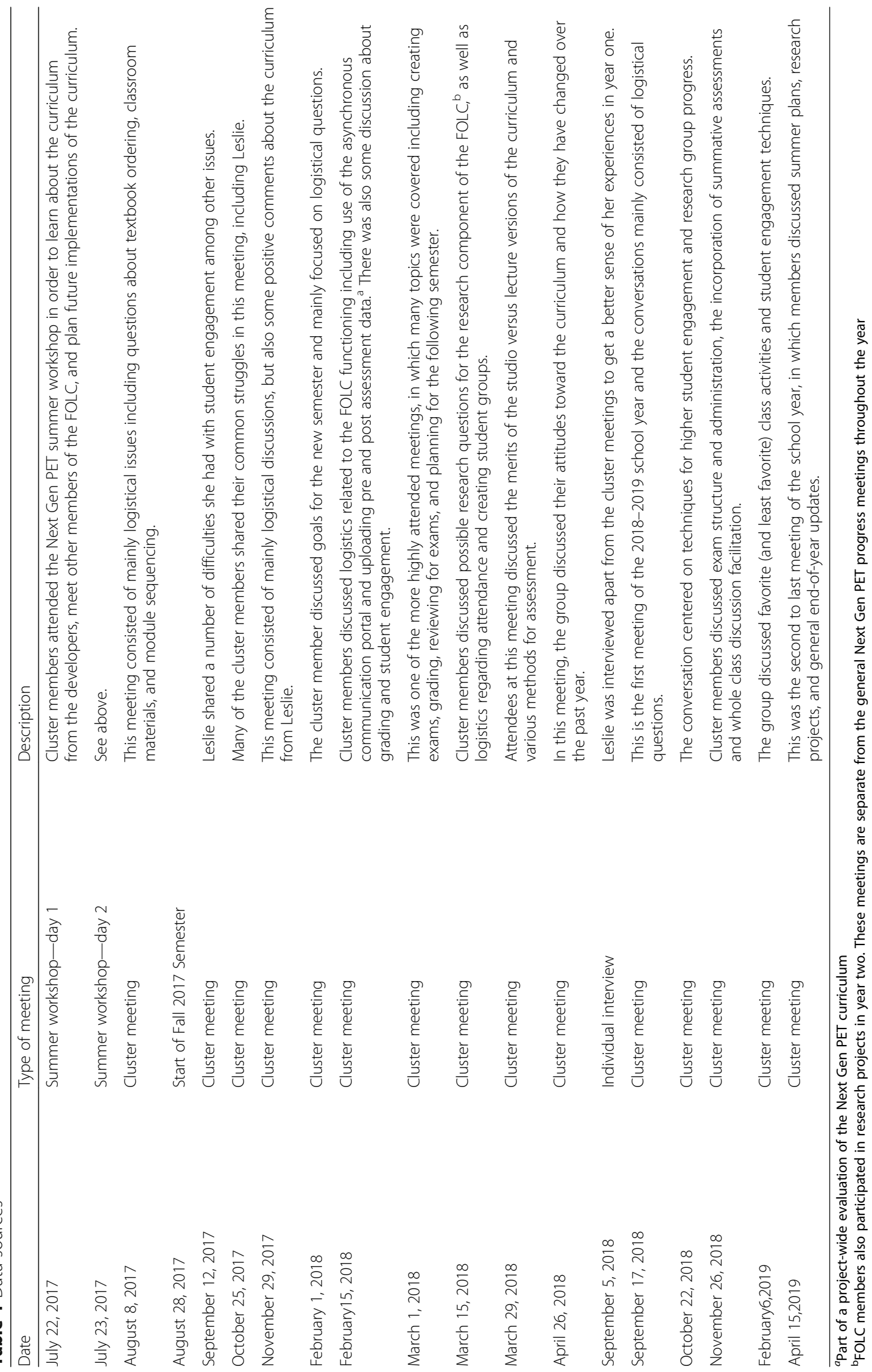




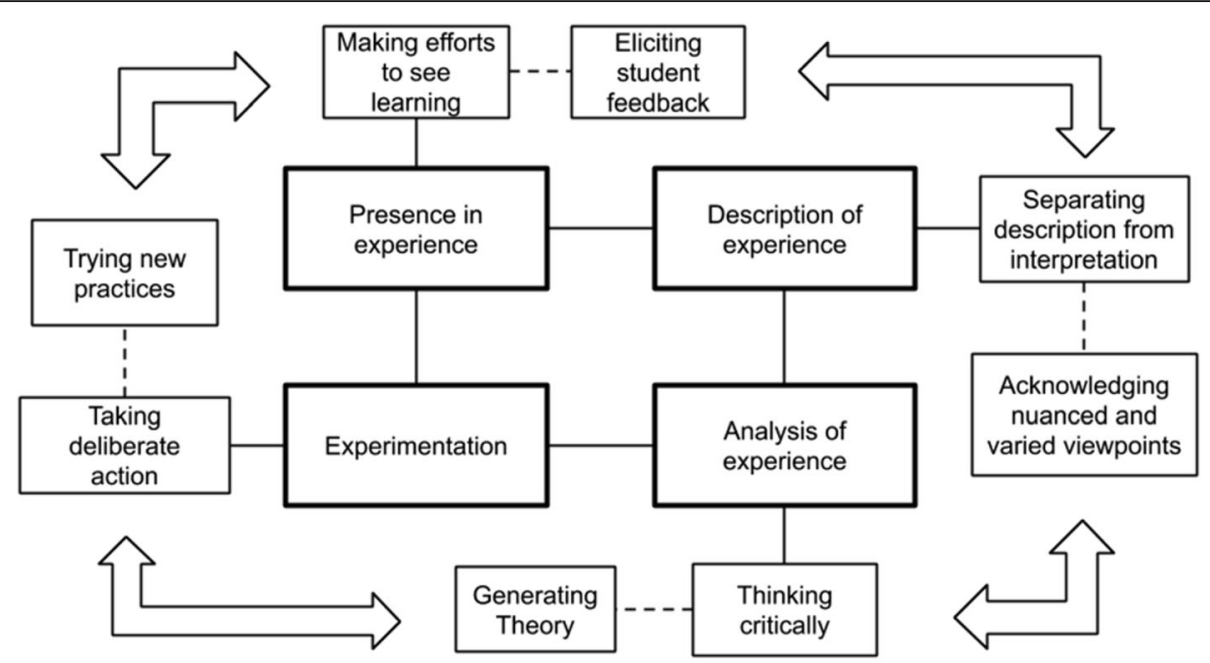

Fig. 2 The expanded version of Rodgers' (2002b) cycle of reflection. The original phases are bolded and additional actions within each phase, from the existing literature, are included in the branching boxes

\section{Results and discussion}

The collection of extant data and subsequent analysis resulted in a description of Leslie's change as she participated in each phase of reflection with the FOLC cluster. First, we will outline how Leslie's reflection process changes over time to lead to changes in both her attitudes and reported teaching practices, which addresses our research question. While there are four distinct phases in Rodger's model, in practice, we observe them occurring without such clear boundaries; therefore, we present the results of the overlapping phases. Then, we will discuss how the FOLC may support Leslie's reflection process. This will provide insight into what can occur within a FOLC and how a FOLC can be beneficial for faculty implementing a new curriculum.

\section{How Leslie's reflection process changes over time}

Leslie demonstrates her presence in the classroom through her descriptions of classroom events. She experiences initial difficulties in her first implementation of the curriculum and does not provide a full description of classroom events prior to analysis. However, she is attentive to student feedback and incorporates it into her practice. Over her time, she begins to welcome other viewpoints (from students and FOLC members) to make sense of her classroom situations. She continually experiments in her classroom and reports back her experiences, thus forcing her to be present in order to debrief and discuss with the FOLC group. Now, we will describe the specific ways in which Leslie participates in the phases and how her participation evolved over time in detail.

\section{Presence in, description, and analysis of experience}

The content and structure of the FOLC meetings are likely large contributors to the development of Leslie's description and analytic skills. Within the FOLC, there is an expectation to share experiences and work through any issues, thus the FOLC provides the motivation for members to be present in their classroom experiences. Leslie often shared stories from her classroom with the group and was also one of the first to offer up her experiences. This is indicative of a reflective attitude, in particular directness. Rodgers (2002a) describes directness as a confidence and trust in one's own experiences, which Leslie often shows through her forthcoming nature. In an early year 1 meeting she shared issues with engagement that she noticed in her classroom. She was the first to share in this early meeting (within the first $2 \mathrm{~min}$ of the meeting) and was open to providing more detail.

Well, I'm doing lecture with a little bit of hands on in 55 minutes twice a... or not 55, 75 minutes twice a week, and we're struggling a little bit. I've got great diversity as far as skillset in my classroom, and keeping the students that have had physics engaged and wanting to interact with this material has been challenging. Not impossible but challenging. (September 12, 2017)

She is probed further and adds:

Well they're jumping to the answer, and they're not participating in the process of getting to the answer, and if they give me that solution-ending answer, and I ask them an open-ended question about it, they kind of flounder and they're a little shocked like, 'Come on, I answered the question. Move on from me.' They wanna [sic] show that they've memorized it. They don't wanna [sic] show that they've learned it enough to explain it, which is surprising 
because these classes, I teach three of them, they're all for future elementary and middle school teachers. They're looking at my class as a box to be checked, not as a way to learn. It's been interesting. (September 12, 2017)

Leslie is open to being candid and sharing her struggles in the classroom; however, she incorporates her own biases clearly in her description. She is open to probing questions, but in her responses, we see a mixing of description and analysis. Immediately after, Leslie shares that her students are having difficulties with the lack of facts to memorize for her upcoming exam.

Here we are, I'm in two and a half weeks, so we've just had five class meetings, and we are halfway through the energy... we're less than six. We're almost near the end of the energy one, and I have a module exam coming up. There's a high level of concern as to... 'We don't have a list of things to memorize and study and regurgitate,' and they're a little worried. (September 12, 2017)

Leslie makes a clear assumption here. She thinks her students want something to memorize and they are worried about the exam because they do not have an explicit list of memorable facts. We continually see these high inference descriptions of her experiences that include her own biases regarding what she thinks students want from their learning experience.

In a later meeting, she provided another description of a classroom situation with a clear connection to her past experience and personal bias.

[The energy unit] was just too, too long. Way too long. And I didn't even get ... My students were like, 'We bought this book and we didn't even do half of it?' Unless they're going to split up the modules, I'm seriously considering not doing the forces at all and just doing my own intro for it... I mean I covered easily twice the material in the same amount of time. I don't know if I did it as well, but I actually get to light and sound in the class. And it was an active learning class before, and this is just painful to me. To not cover the information that they need for their class this year. Because this is for future elementary and middle school teachers that I'm doing. I'd like to teach two semesters of this, and then I could get it all done. (October 25, 2017)

She had a clear expectation of the pacing for her class and how much information she should cover; however, she did not take care to separate her initial biases from her actual experience to uncover why she feels that way, why she thinks her students feel that way, and why this particular curriculum may be designed differently. Even so, we see some indication that she is considering the quality of her teaching when she said she may not have taught the material as well. However, neither her nor the other cluster members delved into this statement to address the extensive intermingling of description and analysis in this statement.

Leslie is later surprised when in that same semester her students reported on many occasions that they liked the curriculum. Leslie exhibited presence here as she actively listened to and sought out feedback; however, the feedback was not what she expected.

Well, I did just a question in class of what they thought of it, and I just asked a couple of students as they were walking out, I was very up front with them that this is a new curriculum, I've never taught these subjects in this way. The four students that I had polled really liked it. Several of them felt they didn't understand as well in high school, they got decent grades, but they understand it better now. I thought for sure, two of them would be very upset at how slow it was going since they had chemistry and had physics. Let me get Josh up to speed. I did energy, then forces, and I'm finishing with the chemistry part of it: matter and interactions. It really, kind of flowed through it all. I sipped the Kool-Aid, now. We'll see how they do. I'm really pleased with when they take a homework assignment for me, if they miss a question they email me and instead of saying, 'Why did I miss it,' they say, 'Why did I miss it, I thought this.' I took that as a huge plus that they are thinking about it before they are answering it. (November 29, 2017)

She said she had "sipped the Kool-Aid," likely meaning that she was, from her point of view, faithful to the intent and design of the curriculum, and this faithfulness to the design has led to better outcomes and more positive feedback. She thought her students disliked the class because the pace was too slow in the beginning, but her check-in revealed otherwise. Her students were actually becoming more comfortable with the curriculum and reported that they were learning something. Her obligations to the FOLC likely motivated this check-in with her students due the expectation of sharing experiences.

In her second implementation (second semester), Leslie was much happier with her class. She reported that she could easily gage whether her students understood the material and were engaged. Even so, Leslie questioned her methods for assessing whether her students were learning. She wanted to know how other FOLC members did this, likely to inform her own practice. 
I'm much more comfortable with the Next Gen PET this semester, even starting it out, even with the time frame. That's why I'm working on my pacing a little bit better. I always feel I know if my students are getting it or not. I have activities where they do specific things and they gather. I'll walk around the room and I'm listening for certain things, or I'll collect something, a quick assignment, and I'll look through what they're actually getting back. But, ultimately, I'm relying on how they perform on an exam. I would be curious to find out what other people do or know. I mean it's one thing to get comfortable with the curriculum and say, 'Yeah, they're getting it because they're smiling at me' ...If they're engaged, I'm thinking I'm doing good. I'm curious what other people think or what means success for them. (February 1, 2018)

Her concerns regarding student learning came up earlier as well when she mentioned creating "an exam that actually tests them [sic] thinking" (September 12, 2017). She continually centered students when describing classroom experiences. She conveyed that she wanted to uncover their thinking and learning and assess how they are doing. She felt she had a good sense for how her students were doing and if they were learning, but she continued to seek other methods of assessment to improve her skills. This is consistent with the goals of the reflective cycle as there is a requirement of student-centeredness and an earnest commitment to improvement.

In her second implementation, she clearly worked to be present and pay attention to her students. She reported being better at implementing the curriculum the second time around, which makes sense as she had taught the exact course once before and had some expectations of what her students would do and say.

And this year, what I noticed was really good, pace very interesting class. And these are my [general education] students. So I was pretty good... And knowing that students found it confusing and I didn't really get into the process of it the first, last fall semester. I trusted the process more when I started out this semester. And I'm sure that's the correlation to why they're finding it more interesting and there was more class interaction there was more completion of the extensions and places and things like that. So my... I got up to speed. (April 26, 2018)

Leslie had a better understanding of the curriculum, what she must do to prepare for class facilitation, and what her students should do. This was echoed in her one-on-one interview, which was administered following her second implementation.
I liked the fact that they're coming to the laws and the rules on their own and they're experiencing them and they're drawing those conclusions on their own, instead of the outline that says, these are the overlying rules thing ideas that you should have at the end of it. It's really putting them in charge of being engaged in the course while they're in the class. (September 5, 2018)

Leslie valued her students' independence and agency. She was happy that they were engaging in the process and drawing their own conclusions. She was not concerned with teaching well per se, but providing opportunity for her students to learn, which is a key goal in the reflective cycle as teachers and students become "partners in inquiry."

Despite the strides Leslie has made in centering learning and eliciting student feedback, Leslie continually struggled with considering others' opinions and challenging her own assumptions. She reached a breakthrough in year two when one FOLC member questioned her engagement techniques. When asked what happens when engagement techniques do not work at all, she said:

I guess it's me then because they don't get to not talk in my class because they'll say, 'I don't know,' and I'm like, 'Yeah, but if you did know. What would you say?' And then they're like, 'I have to come up with something.' (February 6, 2019)

After the same faculty member pressed further, she acknowledged that sometimes engagement techniques do not always work and it is not necessarily the fault of the educator, but that one must be responsive to the class and meet them where they are. This demonstrates Leslie's commitment to presence and reveals her amenability to other points of view, particularly of her students. Though we do not have direct classroom observation data, it can be inferred through her comments at the meetings that Leslie is deeply present in her class and is responsive to her students' ideas. She added that her class size was small and that likely helped with getting students to talk. In addition, she acknowledged her own talkative nature likely contributed to why her students were willing to communicate with each other in class and that she could only speak from her own personal experience. These comments may have come off as somewhat authoritative, but to an audience that knows her well, it was likely that these strong opinions were provided because she was more confident in her answers than she had been in year one. She was firm in her assertions, but also understanding and open to other viewpoints, including the fact that not all faculty members are as outgoing and talkative as her and as a result may 
struggle more with engagement. From this interaction, we saw Leslie start to move away from her highly biased descriptions and attempt to incorporate differing viewpoints into her descriptions and analysis of situations. This is integral to the description and analysis phases of reflection and shows her growth as a reflective educator.

\section{Experimentation and reporting back}

Leslie began to trust the curriculum design more in her second implementation, which led to an apparent increase in confidence in the curriculum. In addition, a majority of Leslie's instances of experimentation and reporting back occurred in her second implementation and beyond. Leslie's increase in confidence and simultaneous experimentation and reporting out culminated in an overall satisfaction with the curriculum that she did not hold previously.

She initially referred to the curriculum as "slow" and "painful"; however, despite her initial complaints Leslie was pleasantly surprised by the student feedback she received and over time trusted the curriculum design more. It took time for her to understand the intent of the curriculum and truly buy into it.

I also preface my class for this semester like, 'It's going to start out really painfully slow.... Stick with me, because I'm going to speed up. And if you stay with me, you'll be able to increase the pace and still have this.' (March 1, 2018)

She still felt the pacing was slow, but by now it seemed she better understood that a slower pace was useful in giving her students time to think more deeply about the material and to develop understandings of why certain phenomena happen the way they do, without the need to memorize rules or facts. As her students became comfortable with the class and format, she would be able to speed up because she knew that they were capable of engaging in the process at a faster pace. Her statements in the March 1,2018 meeting demonstrated a deeper understanding of the intent of the structure of the curriculum, which allowed her students to reason about scientific concepts in their own words through in-class discussion.

By Leslie's third implementation she had reported back that she was even more confident in her approach and was able to address more material in class that she had in any of her previous implementations.

So, I'm going to make it all through energy, through both units of forces and through physical change and all but one lesson of chemical reactions. That's the farthest I've ever made it. ...and one of the things that I did this year that I felt much more confident about to do with these pre-service teachers is to say, 'Look, the first part we're doing it the way you would with your students and it's all going to be this exploratory and you talk a lot.' But, then it's we're into the chemistry part of it and they understand how the class flows, there's PowerPoints, there's extensions and so forth. I said, 'I'm ramping up the pace, not to cover more material so much as, you're in college, you can handle this pace.' I'm not getting pushback from it. They accepted that. They're much more comfortable this year because I'm more comfortable with the extensions and looking at them and then going and taking the quizzes. (November 26, 2018)

Leslie reported that she felt more confident and as a result her students also felt more confident. She continued to improve upon her pacing through a thorough explanation of the process (of the curriculum) and also taking into account the abilities of her class and the pace that they as a whole would be able to handle. This attentiveness to her students' needs, again demonstrating presence, led to a more successful implementation.

When Leslie reflected on her first year of teaching the new curriculum, in a one-on-one interview, she reported that she had become more comfortable with allowing her students more responsibility and agency in their learning.

In the beginning it was different and... it was a learning curve to sit back and let the class discuss what they saw. And now I feel I'm okay with doing that and very comfortable with giving them time to discuss what they see. And come up with their answer and say, Okay, we're going to go on and they'll be like, 'What's the right answer?' I'm like, 'Well, what'd you put?' We don't know if it's right. Yeah, well, maybe we'll figure it out in the course of this class, whether or not it was right or not. So letting the students stew in their frustration, a little bit. I'm okay with yeah. (September 5, 2018)

She communicated the importance of agency and student-centeredness and reported on many occasions that her students were receptive to that directness and acted accordingly. She noticed that her students were comfortable with the consensus approach that the curriculum takes and that she was also more comfortable with her students figuring things out on their own.

Leslie likely began to experiment with the curriculum more frequently, due to her increasing confidence in the curriculum. Leslie often shared new techniques she incorporated in her class.....for the first time [I] embraced a program app called Gradescope where I scanned all of [the exams] and I was able to give them specific feedback..." 
(February 15, 2018). One of other cluster members was particularly interested in this technology and Leslie provided more details for her. In this instance, she was able to give back to other cluster members in addition to benefiting from the FOLC. Leslie not only incorporated new techniques and technologies she found on her own but also incorporated ideas from other cluster members.

So then I took a page out of Corey's class, because I gave one of my unit exams online. And I said, look, I would like to say do it on your own and it's timed, but not everybody's going to follow those rules. So I made it open note, open book, open colleague it in this class and they had 90 minutes to take a test, they would normally only have 55 minutes to take in a classroom because they said you're going to be going through your notes and whatever. And right now it's that's open and I'm running about a 78\%, which is what I would have had in a paper exam. But we'll see how it ends up once they all take it because only about a little over half, maybe five eighths of taking it. So we'll, we'll see. (April 26, 2018)

Leslie moved from in-class to online exams due to a suggestion from another cluster member. She not only took this advice but reported back on her results. Due to the timing of the cluster meetings, Leslie did not report on the final grade from those exams but did continue to use and improve upon the online take-home test format in her third implementation of the course. "So I took to heart what you were saying about group tests and I think I'm going to give my... after the first test. The rest of them as take home tests... together," (September 17, 2018). She was convinced by one of the cluster leaders that allowing her students to take online group tests would be beneficial for them because they would learn more that way.

In a later meeting, she pointed out that one of the cluster leaders "inspired [her] that it was okay to give them a take-home test," (November 26, 2018). She may have had previous notions about take-home exams not being beneficial but was convinced by a trusted other in the FOLC that it could work. From her experience with online take-home tests, she also reported back that it was beneficial to give the first exam in person before using the online format.

I don't recommend giving the first one online. I don't because... and I feel very strongly about this... whenever you take a test... there's assumptions in that question and by the end of the first month... they don't have enough under their belt to know what kind of test question I'm going to ask. So, I really like having them take that first test with me. And I'm like 'If you have a question, raise your hand, I will come to you.' (November 26, 2018)

Leslie was able to optimize the exam format for the needs of her class. She reasoned that students may not understand the intent of the exam questions and that her presence as a resource would be valuable to her students as they became accustomed to the format of the class. She took into account not only the viewpoints of other cluster members, but the viewpoints of her students in order to inform and improve her teaching practice. From this, we see that Leslie continually improved upon her exam format over the course of her participation in the FOLC through multiple cycles of experimentation and reporting back.

\section{How the FOLC supports Leslie's process of change}

Leslie directly attributes her success to the FOLC at the final meeting of year two.

I've enjoyed being able to get feedback and ideas and encouragement for trying something new and I'm definitely doing something different than anybody else is in my department and the feedback that I got from my students is enough to make me want to keep doing something of this sort. I tweaked it a little bit. Seems to fit my students better, but your students change from semester to semester. So, I feel like I'm building my repertoire, but I'm really appreciative of you, Chester and Chelsea and Natalie and Luli and everybody's ideas, I take it. I write it down. I probably don't create anything new, just steal everybody else's good ideas. So, thank you. Thank you very much. (April 15, 2019)

Leslie shared an extensive summary of her attitudes about the course and how the social interactions within the FOLC have influenced her teaching practice. She was appreciative of feedback and ideas from the FOLC, which provided new lenses from which she could analyze her experiences. Finally, though she did not think she created something new, she reported that she was able to change and optimize her class in order for her students to be successful, in part from what she learned in the FOLC. Over her 2 years of participation in the FOLC, she was able to reflect on her classroom experience and make meaningful changes to a predesigned curriculum to fit her students' needs.

The context of the FOLC provided a stage for Leslie to describe her issues and troubleshoot problems. The norms of candidness in sharing classroom experiences and ongoing support promoted each of the four phases of reflection. Through each iteration, Leslie becomes 
more comfortable and satisfied with the curriculum. It can be concluded that the context of the FOLC was integral to Leslie's participation and growth as an instructor. The commitment to the curriculum that the FOLC encouraged likely kept Leslie accountable in improving her implementation of the curriculum.

There is also an expectation of struggle when implementing a new curriculum and the availability of support from the FOLC likely pushed Leslie through the "implementation dip" that most instructors face (Fullan, 2007). She emerged on the other side of the dip with a deeper understanding and appreciation of the curriculum. As a result, Leslie was able to cover more material while simultaneously observing greater approval of and engagement in the curriculum from her students. After 2 years in the FOLC, Leslie was more satisfied with the course and reported that she and her students had a clearer understanding of the intent of the curriculum.

\section{Limitations}

As stated previously, the data for this study mainly consisted of recordings of FOLC meetings. As a result, not all of Leslie's classroom experiences were reported, as direct observations of her classroom practices were not conducted. Only the experiences that she found useful to share were included in the analysis; therefore, there is some inherent bias within the data. However, based on her interactions in the FOLC, it was clear that Leslie was active in sharing with the group and frequently provided detailed accounts of her experiences that were useful for data analysis. Also, Leslie may have had other resources outside of the FOLC that may have contributed to her success that were not captured in the monitoring of the FOLC including any reflection she engaged in on her own or with colleagues outside of the FOLC.

A majority of the data accessed is extant data from a larger research project with intersecting lines of research. Thus, most data collection was not tailored to a case study including extant interview data. However, the amount of extant data was sufficient for a case study as we were able to access hours of meeting videos, multiple workshop videos, surveys, and an interview. This analysis is only meant to provide evidence of some of the personal and social resources that may have supported Leslie in reflecting and enacting lasting change in her attitudes and teaching practices.

\section{Conclusions}

Despite the wealth of DBER efforts and RBISs that have been developed and disseminated to faculty and other practitioners, the use and success in implementation of those strategies is still inconsistent (Henderson et al., 2011; Henderson et al., 2012; Seymour, 2002). There is evidence that communities of peers or critical friends, that provide support throughout implementation, may contribute to the adaptation and continued use of new teaching practices (Dancy et al., 2019; DarlingHammond \& Richardson, 2009; Hatton \& Smith, 1995; Sturtevant \& Wheeler, 2019). Community support in combination with individual willingness to reflect on and discuss past teaching experiences could contribute to an increase in the success and consistent use of RBISs.

One motivation for conducting this case study was to better understand the experiences of individual FOLC members. We intended to uncover how participation in the Next Gen PET FOLC was beneficial to faculty, and if it promoted change over time. In order to do this, we adapted and applied Rodgers' cycle of reflection to illustrate one faculty member's experience. Rodgers' cycle consists of four phases: presence, description, analysis, and experimentation. The four phases function as a continuous cycle through which teachers can continually hone their teaching practice. The cyclical nature of this framework allows us to make sense of and describe Leslie's reflection and participation in the FOLC over time. One reason the Rodgers' reflection cycle framework was appropriate for this analysis was because participation in the FOLC and implementation of the curriculum occur contemporaneously. This promotes presence in classroom experience and allows for experimentation through deliberate changes in teaching practices. As well, the community aspect of FOLCs directly supports reflection and is a key criterion for success in participation in reflection.

Through the lens of Rodgers' cycle of reflection and criteria for reflection, we were able to track changes in the way Leslie reflected in the Next Gen PET FOLC. We found that, consistent with reflection criteria, Leslie was better able to take into account the perspectives of others as she continually participated in reflection. Leslie was initially attentive to student feedback as she was implementing a new course, though it was not clear if she used that information in practice. However, over time Leslie began to take into account student perspectives in order to better tailor her class to her students' needs. She also incorporated perspectives of other FOLC members, as demonstrated through her implementation of various techniques brought forth in meetings. Through constant experimentation and optimization of her course and attentiveness to student feedback, Leslie was ultimately able to increase her confidence in her teaching practices. In the process, she also gained an appreciation and deeper understanding of the intent of the curriculum design. Through participation in the FOLC, Leslie was able to better reflect on her experiences and improve her teaching practices, which coincided with her persistence in using the curriculum. Without the 
FOLC, Leslie may have still reflected on her issues alone or with other faculty at her own institution, but with the addition of a shared curriculum and goals and a group of critical friends in the FOLC, Leslie underwent noticeable changes to her teaching and reflective. We consider this a form of teacher change as Leslie was able to make changes to her practice through professional activity, in this case through participation in the FOLC.

While one should not generalize from a single case study, these results point to the value of long-term learning communities, in which faculty can be candid in discussing and reflecting on their teaching experiences and be supported as they seek to improve their practice. As Leslie participates in the FOLC and engages in reflection, we see her persisting through the implementation dip in order to improve her adaptation of the Next Gen PET curriculum. This is just one example of what may unfold within a FOLC but provides evidence that participation in learning communities that provide continuous support such as these can be beneficial for instituting teacher change and supporting that change long-term.

\section{Supplementary information}

Supplementary information accompanies this paper at https://doi.org/10. 1186/s40594-020-00221-8.

Additional file 1:. FOLC case study interview protocol

Additional file 2:. FOLC case study interview transcript

\section{Abbreviations}

Next Gen PET: Next Generation Physical Science and Everyday Thinking; RBIS: Research-based instructional strategies; FOLC: Faculty online learning community; DBER: Discipline-Based Education Research; FLC: Faculty learning community; NGSS: Next Generation Science Standards; PD: Professional development

\section{Acknowledgements}

We thank the faculty members of the Next Gen PET FOLC that participated in this research study as well as Alexandra Lau and Melissa Dancy for feedback on the final manuscript.

\section{Authors' contributions}

AC composed a draft of all sections of the manuscript. FG and EP aided in outlining the manuscript prior to writing. EP, FG, and $C T$ collaborated with $A C$ in composing the final form of the manuscript. AC analyzed the data with input from FG, EP, and CT. All authors read and approved the final manuscript.

\section{Authors' information}

Not applicable.

\section{Funding}

This material is based upon work supported by the National Science Foundation grant NSF DUE-1626496.

\section{Availability of data and materials}

Curriculum available at https://nextgenpet.activatelearning.com. The interview protocol and transcript are available in the supplemental files. Survey data and meeting transcript files are not publicly available due to confidentiality concerns.

\section{Competing interests}

Authors (EP and FG) are involved in designing and running the NGPET FOLC project, including online community facilitation and curriculum development and design.

\section{Author details}

${ }^{1}$ Center for Research in Mathematics and Science Education, San Diego State University, 6475 Alvarado Road, Suite 206, San Diego, CA 92120, USA. ${ }^{2}$ Center for Research in Mathematics and Science Education, San Diego State University, 6475 Alvarado Road, Suite 128, San Diego, CA 92120, USA. ${ }^{3}$ Department of Physics, California State University San Marcos, 333 South Twin Oaks Valley Road, San Marcos, CA 92096, USA. ${ }^{4}$ Department of Physics, University of Maryland, Toll Physics Building, College Park, MD 20742, USA.

Received: 14 October 2019 Accepted: 22 April 2020

Published online: 18 May 2020

\section{References}

Activate Learning. (2018). Next Gen Physical Science in Everyday Thinking. https://nextgenpet.activatelearning.com

Bali, M., \& Caines, A. (2018). A call for promoting ownership, equity, and agency in faculty development via connected learning. International Journal of Educational Technology in Higher Education, 15(1), 46.

Beauchamp, C. (2015). Reflection in teacher education: issues emerging from a review of current literature. Reflective Practice, 16(1), 123-141.

Bernard, H. R. (1988). Research methods in cultural anthropology. Sage Publications.

Blayone, T. J., Barber, W., DiGiuseppe, M., \& Childs, E. (2017). Democratizing digital learning: theorizing the fully online learning community model. International Journal of Educational Technology in Higher Education, 14(1), 13.

Clarke, D., \& Hollingsworth, H. (2002). Elaborating a model of teacher professional growth. Teaching and Teacher Education, 18(8), 947-967.

Cox, M. D. (2004). Introduction to faculty learning communities. New Directions for Teaching and Learning, 2004(97), 5-23.

Creswell, J. W., \& Poth, C. N. (2017). Qualitative inquiry and research design: Choosing among five approaches. Sage Publications.

Czajka, C. D., \& McConnell, D. (2016). Situated instructional coaching: A case study of faculty professional development. International Journal of STEM Education, 3(1), 10.

Dancy, M., Lau, A. C., Rundquist, A., \& Henderson, C. (2019). Faculty online learning communities: A model for sustained teaching transformation. Physical Review Physics Education Research, 15(2), 020147.

Darling-Hammond, L., \& Richardson, N. (2009). Research review/teacher learning: What matters. Educational Leadership, 66(5), 46-53.

Dewey, J. (1933). How we think (original work published 1910). Prometheus Books.

Dewey, J. (1938). Experience and education. Macmillan: Collier Books.

Dweck, C. (2014). Teachers' mindsets: "Every Student has Something to Teach Me" feeling overwhelmed? Where did your natural teaching talent go? Try pairing a growth mindset with reasonable goals, patience, and reflection instead. It's time to get gritty and be a better teacher. Educational Horizons, 93(2), 10-15.

Dweck, C. S. (2008). Mindset: The new psychology of success. Random House Digital, Inc.

Emerson, J. D., \& Mosteller, F. (2000). Development programs for college faculty: Preparing for the twenty-first century. Educational Media and Technology Yearbook, 25, 26-42.

Engelhardt, P., Robinson, S., Price, E., Smith, S., \& Goldberg, F. (2018, August 1-2). Developing a conceptual assessment for a modular curriculum. Paper presented at Physics Education Research Conference 2018, Washington, DC. https://www.compadre.org/Repository/document/ServeFile.cfm?ID=14781 $\& D o c \mid D=4928$.

Erdmann, R., Miller, K., \& Stains, M. (2020). Exploring STEM postsecondary instructors' accounts of instructional planning and revisions. International Journal of STEM Education, 7(1), 1-17.

Freeman, S., Eddy, S. L., McDonough, M., Smith, M. K., Okoroafor, N., Jordt, H., \& Wenderoth, M. P. (2014). Active learning increases student performance in science, engineering, and mathematics. Proceedings of the National Academy of Sciences, 111 (23), 8410-8415.

Fullan, M. (2007). Leading in a culture of change. John Wiley \& Sons. 
Gero, G. P. (2013). What drives teachers to improve? The role of teacher mindset in professional learning (Publication No. 3605669). [Doctoral dissertation, The Claremont Graduate University]. ProQuest Dissertations and Theses Global.

Goldberg, F. (2015). Next Generation PET: Preparing elementary teachers for the NGSS. American Association of Physics Teachers Winter 2015. American Association of Physics Teachers Winter 2015, San Diego, CA.

Goldberg, F., Otero, V., \& Robinson, S. (2010). Design principles for effective physics instruction: A case from physics and everyday thinking. American Journal of Physics, 78(12), 1265-1277.

Goldberg, F., Price, E., Robinson, S., Boyd-Harlow, D., \& McKean, M. (2012). Developing the learning physical science curriculum: Adapting a small enrollment, laboratory and discussion based physical science course for large enrollments. Physical Review Special Topics - Physics Education Research, 8(1), 010121

Goldberg, F., Robinson, S., Otero, V., Kruse, R. and Thompson, N. (2008). Physical science and everyday thinking (2nd edition). It's About Time.

Goldberg, F., Robinson, S., Price, E., Harlow, D., and McKean, M. (2012). Learning physical science. It's About Time.

Guskey, T. R. (2002). Professional development and teacher change. Teachers and Teaching, 8(3), 381-391.

Harlow, D., Otero, V. K. Leak, A. E., Robinson, S., Price, E. \& Goldberg, F. (in press). Learning about teaching and learning while learning physics: An analysis of 15 years of responsive curriculum development. Physical Review Physics Education Research

Hatton, N., \& Smith, D. (1995). Reflection in teacher education: Towards definition and implementation. Teaching and Teacher Education, 11(1), 33-49.

Henderson, C., Beach, A., \& Finkelstein, N. (2011). Facilitating change in undergraduate STEM instructional practices: An analytic review of the literature. Journal of Research in Science Teaching, 48(8), 952-984.

Henderson, C., Cole, R., Froyd, J. E., Friedrichsen, D., \& Stanford, C. (2016). Designing for sustained adoption: A model of developing educational innovations for successful propagation. Physical Review Physics Education Research, 12(1), 010112.

Henderson, C., Dancy, M., \& Niewiadomska-Bugaj, M. (2012). Use of researchbased instructional strategies in introductory physics: Where do faculty leave the innovation-decision process? Physical Review Special Topics - Physics Education Research, 8(2), 020104

Henderson, C., \& Dancy, M. H. (2007). Barriers to the use of research-based instructional strategies: The influence of both individual and situational characteristics. Physical Review Special Topics - Physics Education Research, 3(2), 020102.

Henderson, C., \& Dancy, M. H. (2008). Physics faculty and educational researchers: Divergent expectations as barriers to the diffusion of innovations. American Journal of Physics, 76(1), 79-91.

Horn, I. S. (2007). Fast kids, slow kids, lazy kids: Framing the mismatch problem in mathematics teachers' conversations. The Journal of the Learning Sciences, 16(1), 37-79.

Horn, I. S., Garner, B., Kane, B. D., \& Brasel, J. (2017). A taxonomy of instructional learning opportunities in teachers' workgroup conversations. Journal of Teacher Education, 68(1), 41-54.

Horn, I. S., \& Little, J. W. (2010). Attending to problems of practice: Routines and resources for professional learning in teachers' workplace interactions. American Educational Research Journal, 47(1), 181-217.

Jay, J. K., \& Johnson, K. L. (2002). Capturing complexity: A typology of reflective practice for teacher education. Teaching and Teacher Education, 18(1), 73-85.

Lead States, N. G. S. S. (2013). Next generation science standards: For states, by states.

Mälkki, K., \& Lindblom-Ylänne, S. (2012). From reflection to action? Barriers and bridges between higher education teachers' thoughts and actions. Studies in Higher Education, 37(1), 33-50.

Otero, V. K., \& Gray, K. E. (2008). Attitudinal gains across multiple universities using the Physics and Everyday Thinking curriculum. Physical Review Special Topics Physics Education Research, 4(2), 020104.

Rodgers, C. (2002a). Defining reflection: Another look at John Dewey and reflective thinking. Teachers College Record, 104(4), 842-866.

Rodgers, C. R. (2002b). Seeing student learning: Teacher change and the role of reflection. Harvard Educational Review, 72(2), 230.

Sawada, D., Piburn, M. D., Judson, E., Turley, J., Falconer, K., Benford, R., \& Bloom, I. (2002). Measuring reform practices in science and mathematics classrooms: The reformed teaching observation protocol. School Science and Mathematics, 102(6), 245-253.
Seymour, E. (2002). Tracking the processes of change in US undergraduate education in science, mathematics, engineering, and technology. Science Education, 86(1), 79-105.

Smith, P. S. \& Wingard, K. (2019). Next generation physical science and everyday thinking faculty online learning community: annual evaluation report year three.

Sturtevant, H., \& Wheeler, L. (2019). The STEM Faculty Instructional Barriers and Identity Survey (FIBIS): Development and exploratory results. International Journal of STEM Education, 6(1).

Tinnell, T. L., Ralston, P. A., Tretter, T. R., \& Mills, M. E. (2019). Sustaining pedagogical change via faculty learning community. International Journal of STEM Education, 6(1), 1-16.

Wesley, P. W., \& Buysse, V. (2001). Communities of practice: Expanding professional roles to promote reflection and shared inquiry. Topics in Early Childhood Special Education, 21(2), 114-123.

\section{Publisher's Note}

Springer Nature remains neutral with regard to jurisdictional claims in published maps and institutional affiliations.

\section{Submit your manuscript to a SpringerOpen ${ }^{\circ}$ journal and benefit from:}

- Convenient online submission

- Rigorous peer review

- Open access: articles freely available online

- High visibility within the field

- Retaining the copyright to your article

Submit your next manuscript at $\boldsymbol{\nabla}$ springeropen.com 